\title{
SCRAPBOOKING AS A TOOL FOR TRANSDISCIPLINARY PROFESSIONAL LEARNING ABOUT HIV AND AIDS CURRICULUM INTEGRATION IN HIGHER EDUCATION
}

\author{
L. van Laren* \\ e-mail: vanlarenl@ukzn.ac.za
}

\section{K. Pithouse-Morgan*}

e-mail: pithousemorgan@ukzn.ac.za

*University of KwaZulu-Natal

School of Education

Durban, South Africa

\author{
C. Volks** \\ e-mail: cal.volks@uct.ac.za
}

\section{ABSTRACT}

We worked together as a group of four researchers at two different institutions to explore scrapbooking as a tool for professional learning about HIV and AIDS curriculum integration in higher education. Through a scrapbooking activity we individually and collectively made visible experiences and understandings of being HIV and AIDS curriculum integrators that are hard to put into words. We used found poetry as a research practice to gain deeper understanding of HIV and AIDS curriculum integration, while also learning more about how visual and literary arts-based methods can enhance individual and collaborative professional learning. Our scrapbook pages and poem offered a multifaceted, nuanced portrayal of curriculum integration as complex, challenging and rewarding. Through collaborative interactions and sharing of our personal images of HIV and AIDS curriculum integration we were able to extend our professional learning in a supportive and creative manner, which fuelled optimism and agency.

Keywords: curriculum integration, found poetry, higher education, HIV and AIDS, professional learning, scrapbooking

\section{INTRODUCTION}

Scrapbooking brings together the visual and narrative arts. Reynolds (2010) describes scrapbooking as a process whereby makers select and arrange scraps - images and objects that have particular connotations - on pages to tell stories, usually about personally significant life events. Increasingly scrapbooks comprise not only physical pages, but also virtual, online pages. While scrapbooking initially evolved as a pastime, usually for women to chronicle family lives, it is being used more and more for professional and research purposes. Research has been done on scrapbooking as a therapeutic tool to facilitate self-expression (particularly 
of thoughts, feelings, and experiences that are hard to put into words) and to enable self-learning and growth through connecting and sharing with supportive others (Kohut 2011; McCarthy and Sebaugh 2011; Williams and Lent 2008). Scrapbooking has also been used as a participatory research method, with the aim of foregrounding the concerns and opinions of research participants (Enright and O’Sullivan 2011; Jones 2007).

In this article we - a team of four academics from two South African higher education institutions - make visible our collaborative exploration of scrapbooking as a tool for professional learning about HIV and AIDS curriculum integration in higher education. Our focus is on how scrapbooking enabled us individually and collectively to initiate and enhance our own learning as university educators (Pithouse-Morgan and Samaras 2015), and the implications thereof for HIV and AIDS curriculum integration in higher education.

We begin our article with a brief summary of HIV and AIDS curriculum integration in higher education. Next we describe the transdisciplinary team members' professional backgrounds and our mutual interest in HIV and AIDS education. Thereafter we explain how we went about exploring our professional learning in the area of HIV and AIDS integration and the making of our individual scrapbook pages, which we used as a visual art-based research method. We go on to provide details about how we drew together our reflections on our scrapbook pages to create a found poem. Butler-Kisber (2005) describes found poetry as the process of using words, phrases and/or paragraphs, found in qualitative data and shaping these selected words into poetry by formatting, spacing, adding and/or deleting works. Thus, using a found poem method, we coalesced our professional learning about HIV and AIDS curriculum integration. This is followed by the framing of our individual and collective learning using the themes 'selfing, distancing and valuing' (Van Laren, Mitchell, Mudaly, Pithouse-Morgan and Singh 2012, 138). We explore and present our collective engagement, through scrapbooking, as a tool for transdisciplinary professional learning in HIV and AIDS curriculum integration.

\section{SETTING THE SCENE}

\section{HIV and AIDS curriculum integration in higher education}

The key findings of the South African National HIV Prevalence, Incidence and Behaviour Survey, 2012 (Simbayi, Shisana, Rehle, Onoya, Jooste, Zungu, Labadarios and Zuma 2014) indicate that overall HIV prevalence increased from 10,6 per cent in 2008 to 12,2 per cent in 2012. Recognising the continuing complexity and pervasiveness of HIV and AIDS in South Africa, the Higher Education HIV and AIDS Programme (HEAIDS) prepared a revised Policy 
and Strategic Framework on HIV and AIDS for Higher Education (HEAIDS 2012). This policy acknowledges the negative impact of HIV and AIDS on the higher education sector: 'Ill health, absenteeism or other increased stress or vulnerability on the part of youth, educators, support staff and officials constitutes a threat to the attainment of teaching and learning education outcomes' (2012, 11). The policy highlights the significant role of education in mitigating vulnerability to HIV and AIDS, alleviating the multiple damaging effects of HIV and AIDS and strengthening capacity to respond to the pandemic. However, the policy developers pointed out that the policy would 'be truly worthwhile only if it guides actual programme implementation' and that it 'requires an integrated institutional approach, and leadership and commitment at all levels' (HEAIDS 2012, 4). The policy thus recognises that integration of issues of HIV and AIDS through curriculum development is essential and necessitates 'the comprehensive and appropriate use of the Higher Education mandate of teaching and learning, research, innovation and knowledge generation, and community engagement' $(2012,24)$.

Curriculum integration is an 'old idea' (Hinde 2005, 105). For example, in the early 1900s Dewey (1938/1997) advocated curriculum integration to facilitate the development of learning experiences that are responsive to learners' interests and needs. There is currently still no single agreed definition of curriculum integration, but Parker (2005, 425-453) summarises the concept of an integrated curriculum by describing it as:

... a curriculum approach that purposefully draws together knowledge, perspectives, and methods of inquiry from more than one discipline to develop a more powerful understanding of a central idea, issue, person, or event. The purpose is not to eliminate the individual disciplines but to use them in combination.

Various models are available for an integrated curriculum. Parker (2005) aligns the models on a continuum. At one extreme of the continuum the learners themselves select the content and process for solving of learner-elected problems, while at the other end of the continuum educators arrange concepts that link similar learning experiences from different subjects. Here subjects remain separate but connections are made between two (or more) subjects.

In addition to the continuum of integrated curriculum models, there are also diverse approaches to integration. According to Hinde (2005) the inclusion of some aspects of one subject into another for the benefit of both subjects is frequently used at primary, secondary and tertiary levels because this allows learners to see connections between and among topics taught in different disciplines.

Since 2009 HEAIDS has been documenting good practice that could help inform models of integration for educators in South African higher education institutions (HEAIDS 2010). 
There are different forms of HIV curriculum integration in institutions, and HEAIDS (2010) lists forms that may be described as stand-alone, integrated into carrier subject, and infused into several modules. However, not all academics are necessarily willing and/or able to take on HIV and AIDS curriculum integration - and those who do use a particular form of curriculum integration can experience challenges and disadvantages (HEAIDS 2010). For example, if the stand-alone model is selected for curriculum integration then a space for this additional module needs to be created in the already overloaded higher education curriculum. If the integrated into carrier subject option is implemented, then only certain aspects of HIV and AIDS can be selected for inclusion in the module, and other equally important aspects will be neglected. When the infusion into several modules model is utilised then a time-consuming, thorough analysis of the existing prescribed curriculum needs to be organised to avoid duplication of HIV and AIDS content.

The complexity of HIV and AIDS curriculum integration means that academics need specific professional learning support when implementing this additional teaching responsibility (Van Laren, Mitchell, Mudaly, Pithouse-Morgan and Singh 2012). The provision of such support requires an in-depth, contextualised understanding of the professional learning experiences of academics who take on the challenge of integration (Van Laren et al. 2012).

In this article we build on and extend three themes that we have identified in previous research on professional learning experiences of academics that choose to take up HIV and AIDS curriculum integration in diverse academic disciplines. These themes, that provide a frame for our discussion, are ‘selfing, distancing and valuing' (Van Laren et al. 2012, 138). First, 'selfing' is associated with seeking ways of transforming personal and academic knowledge to facilitate HIV and AIDS curriculum integration. Second, 'distancing' highlights the wide range of perceptions of academics and students regarding the stretching of disciplinary boundaries to allow (or, alternatively, dismiss) HIV and AIDS curriculum integration. Third, 'valuing' refers to the importance that some academics place on HIV and AIDS curriculum integration and their determination to persist with finding innovative ways of transforming and improving on integration practices.

\section{Transdisciplinary professional learning}

Our research team comprises four female academics from two South African higher education institutions in two different provinces. Two of us are teacher educators (Linda is located in Mathematics Education and Kathleen in Teacher Development Studies), while Cal and Sianne are members of an HIV and AIDS curriculum integration unit, which aims to support and build 
student and staff capacity through curriculum, co-curriculum and social responsiveness initiatives. The number of years each of us has been involved with transdisciplinary work in HIV and AIDS curriculum integration ranges from 3 to 21. We were drawn together by our active involvement in a HEAIDS (2012) Community of Practice (CoP) for HIV and AIDS Education in Higher Education Institutions. As members of the CoP we interact with academics involved in HIV and AIDS education across South African higher education (23 universities and 50 technical vocational education and training institutions). We became acquainted through our attendance at HEAIDS CoP meetings, where we were provided with opportunities to 'collaborate, network, share knowledge and provide collective suggestions on issues related to HIV and AIDS teaching, learning and research’ (De Lange 2014, 1).

After the May 2014 CoP meeting in Boksburg, South Africa, we decided to collaborate to share, reflect on and extend our professional learning about HIV and AIDS curriculum integration in higher education. Our mutual interest in using visual and literary arts-based methods as innovative modes of researching and facilitating professional learning (see, for example, Van Laren, Pithouse-Morgan, Chisanga, Harrison, Meyiwa, Muthukrishna, et al. 2014; Pithouse-Morgan, 2016) informed our decision to try out scrapbooking to enable selfexpression and professional learning through connecting and sharing with each other. Our research question was: How can making and reflecting collaboratively on scrapbook pages serve as a tool for professional learning about HIV and AIDS curriculum integration in higher education?

\section{OUR SCRAPBOOKING PROCESS}

As we are located in two different South African higher education institutions that are approximately $1600 \mathrm{~km}$ apart, we made use of email and Skype (an Internet telephony service that offers free calling between computers) communications for our collaborative exploration of professional learning about HIV and AIDS curriculum integration in higher education. We commenced by arranging a Skype meeting on 31 October 2014. During this virtual meeting we agreed to work collaboratively using the creative technique of scrapbooking. According to Hunting and Conroy $(2011,1)$ scrapbook pages are 'autodriving' as they assist the reflection process. Furthermore, scrapbook pages can afford a focus for collaborative learning through becoming 'key artefacts' (Hunting and Conroy 2011, 2) for connecting, sharing and reflecting with each other. We decided that each researcher should portray herself, her students and her HIV and AIDS curriculum integration process on a scrapbook page. Each team member would decide how best she should portray these three aspects on her scrapbook page. 
For suggestions as to how to make a scrapbook page, Linda circulated two elementary guidelines. The guidelines Basic elements of a scrapbook layout (http://www.everything-aboutscrapbooking.com/scrapbooking-layouts.html) and Fast and easy page layouts for beginners (http://scrapbook.lifetips.com//cat/63172/getting-started-with-scrapbooking/index.html) were emailed to each team member. Each researcher then individually and independently made her own scrapbook page. We each gave our own scrapbook page a title. No further specifications, requirements or guidelines were stipulated as to how the scrapbook page should be created. On 11 November 2014 Linda circulated the following email suggestion for consideration:

It does not matter which digital scrapbooking package you use - as long as each person does hers individually and there are not too many small photographs. Remember that the final product will be black and white.

We were aware of the ethical challenges around selecting and using images for research purposes. We found the clear recommendations for visual ethics set out in Mitchell (2011) useful for guiding our selection of images for our scrapbook pages. We agreed that we would avoid using recognisable images of people that could compromise the anonymity requirement for conducting ethical research.

Each of us took a different approach to creating a scrapbook page. As each team member was required to make her own scrapbook page, her unique creation highlighted what was important to her (Belk and Kozinets 2005). This facilitated self-reflection (Hunting and Conroy 2011) on her own professional learning about HIV and AIDS curriculum integration. We present each of our reflections on our scrapbooking process below, presented in our own words.

\section{Linda's scrapbook page process}

Before making the scrapbook page on 20 November 2014, I decided to select four images that I considered important to display. These selected images were printed onto glossy photographic paper.

First I selected the hand-drawn faces of the seven final-year pre-service teachers who actively worked with me in a voluntary HIV and AIDS Mathematics Education Project. These students provided key information about HIV and AIDS curriculum integration in Mathematics. Their comments and reflections were central to my doctoral thesis (Van Laren 2008). I would have preferred to include a photograph of these pre-service teachers, but it was necessary to use the drawings of their faces to ensure confidentiality.

Second, I asked my daughter to take a photograph of me walking down a street. I considered walking down a street as an appropriate metaphor to represent my initiatives in HIV 
and AIDS curriculum integration at a higher education institution.

Third, I chose a newspaper clipping of an article where the author highlighted the fact that many South Africans die of AIDS but the health statistics do not indicate that these deaths are as a result of AIDS. (The deaths are usually reported as being a result of one of the secondary diseases of AIDS such as TB.) I used this article during an integrated lesson whilst teaching Mathematics Education at a higher education institution.

Fourth, I made a print of a world map that shows the number of people living with HIV and AIDS in the various continents. This map shows how the majority of people living with HIV and AIDS are Africans. This fact, represented on the map, has always disturbed me because I am concerned about people living in our African continent where so many of us are influenced by the pandemic.

For my scrapbook page I selected green as the background on which to mount the four images because this colour is bright and lively. I associate green with growth and this reflects the fact that working with pre-service teachers for HIV and AIDS curriculum integration in Mathematics Education was a home-grown initiative that developed organically.

I did not purchase any of the embellishments for my scrapbook page. I selected buttons, a calculator, ruler, chord and eyelets from my daughter's collection of embellishments. She is an avid scrapbooker who collects and/or purchases various objects that she sees as potential pieces for scrapbook pages.

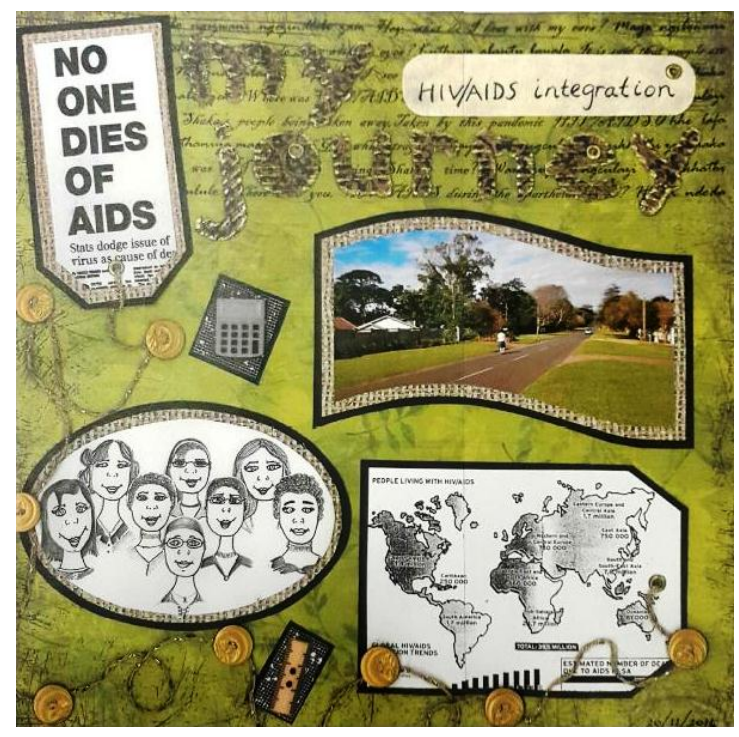

Figure 1: Linda's scrapbook page, 'My HIVIAIDS integration journey'

\section{Kathleen's scrapbook page process}

In creating my scrapbook page, I chose pieces from journal reflections that were written by my students and me during my doctoral research, which was a study of my professional learning 
through teaching three postgraduate teacher education courses at a South African university (Pithouse 2007).

Because the topic of my scrapbook page was 'Me and HIV and AIDS' I specifically looked for reflections that were about bringing self-awareness to HIV and AIDS in education. I printed these reflections and then cut and pasted them by hand onto a page. I used a darker border to frame my students' reflections and a lighter border to frame my reflections. However, I did not label the reflections, so it would not be obvious to anyone other than me which were my reflections and which were student reflections. I wanted to show that there were overlaps between our reflections.

I used paper flowers to connect the reflections. The flowers symbolise new life and growth, but they also symbolise remembrance. The warm pink colour of the background symbolises emotions and care. Linda was kind enough to lend me her daughter's collection of scrapbook paper and embellishments. Linda and I sat together and made our pages.

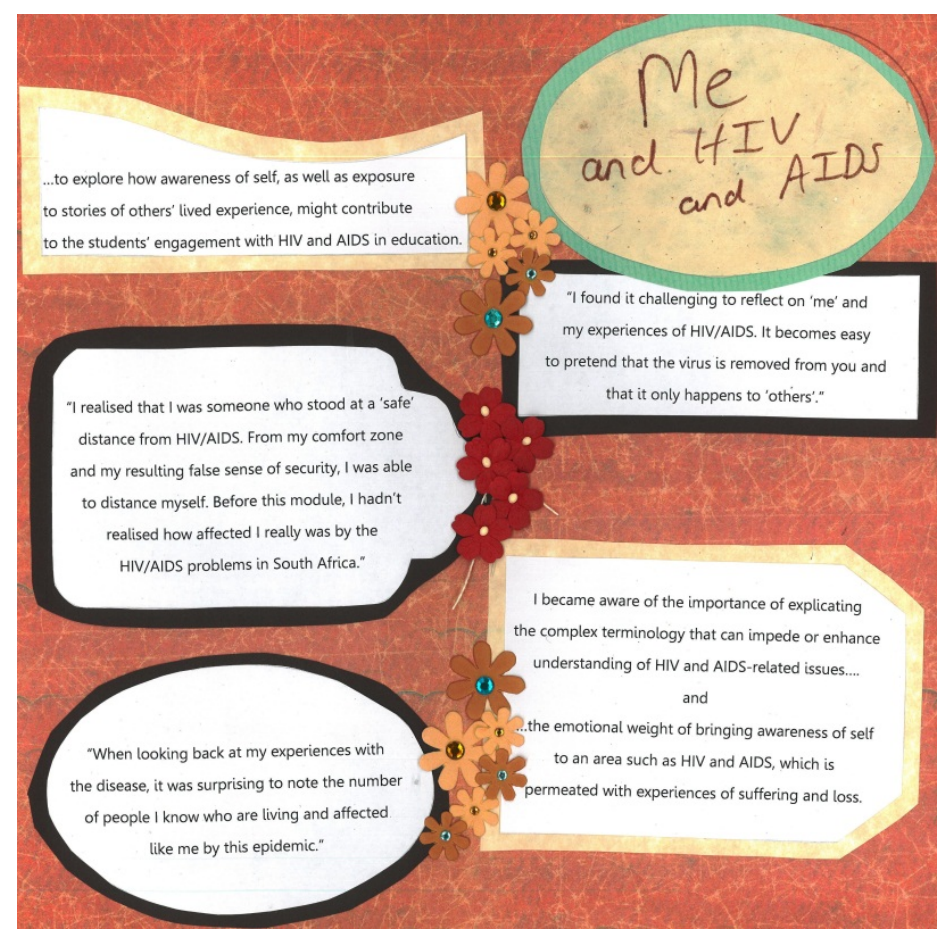

Figure 2: Kathleen's scrapbook page, 'Me and HIV and AIDS'

\section{Cal's scrapbook page process}

My favourite writer is Anne Michaels (2010). She writes about the intergenerational trauma experienced by second- and third-generation Holocaust survivors, which is particularly relevant to South Africa. I also love street art/graffiti because of its use of youth culture, transience (similar to life and youth, which are also both transient) and the ability to make a narrative out of an otherwise unused space. 
While visiting Melbourne for the AIDS Conference in 2014, as I was running to and from conference sessions, I took photos of graffiti. I was particularly drawn to anything to do with love, death and the transience of youth and life. The writer Angela Savage (2014), who writes that she loves both Anne Michaels and graffiti too, puts this well. She quotes from Michaels' novel The Winter Vault (2009):

Avery spoke of the despair of space that the built world had created; waste space too narrow for anything but litter; dark walkways from car parks to the street; the endless, dead space of underground garages; the corridors between skyscrapers; the space surrounding industrial rubbish bins and ventilator shafts ... the space we have imprisoned between what we have built, like seeds of futility, small pockets on the earth where no one is meant to be alive, a pause, an emptiness ... (as cited in Savage 2014, para. 2)

Savage (2014, para. 3) writes:

And that's why I love street art ... - and I include graffiti in my definition - because it transforms 'waste space' into something of value, breathing life into those small pockets where no one is meant to be alive, filling that emptiness with something to ponder, admire, take umbrage at, get excited about ...

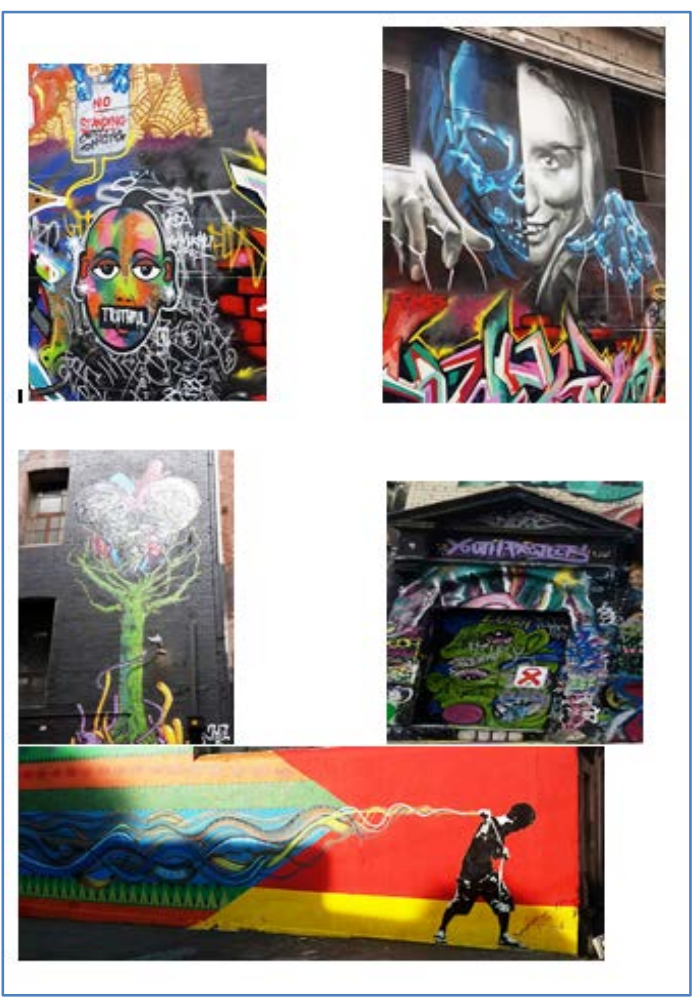

Figure 3: Cal's scrapbook page, 'Youth art/health Xchange'

I am drawn to graffiti because it so often reflects the artistic expressions and concerns of young people the same age as those we are targeting with HIV education. The images speak to young people sometimes more than words. I was particularly drawn to taking photographs of graffiti that symbolised themes associated with HIV which we teach around: love, freedom, how one 
can be HIV positive and no one can know, the vibrancy and precious nature of life and the way it affects young people because they are at an experimental developmental stage in life. I wanted to use the images in refining what I want to teach about HIV and AIDS.

\section{Sianne's scrapbook page process}

I was interested in the parallel developments of education moving into an online arena and the use of interactive software as a pedagogical tool within the lecture room. This interest influenced my choice in selecting an online medium to present my scrapbook. Using the digital Smile scrapbook software I chose a digital journal design that allowed for maximum layering of scrapbooking effects such as texture, layers of paper, colour and text.

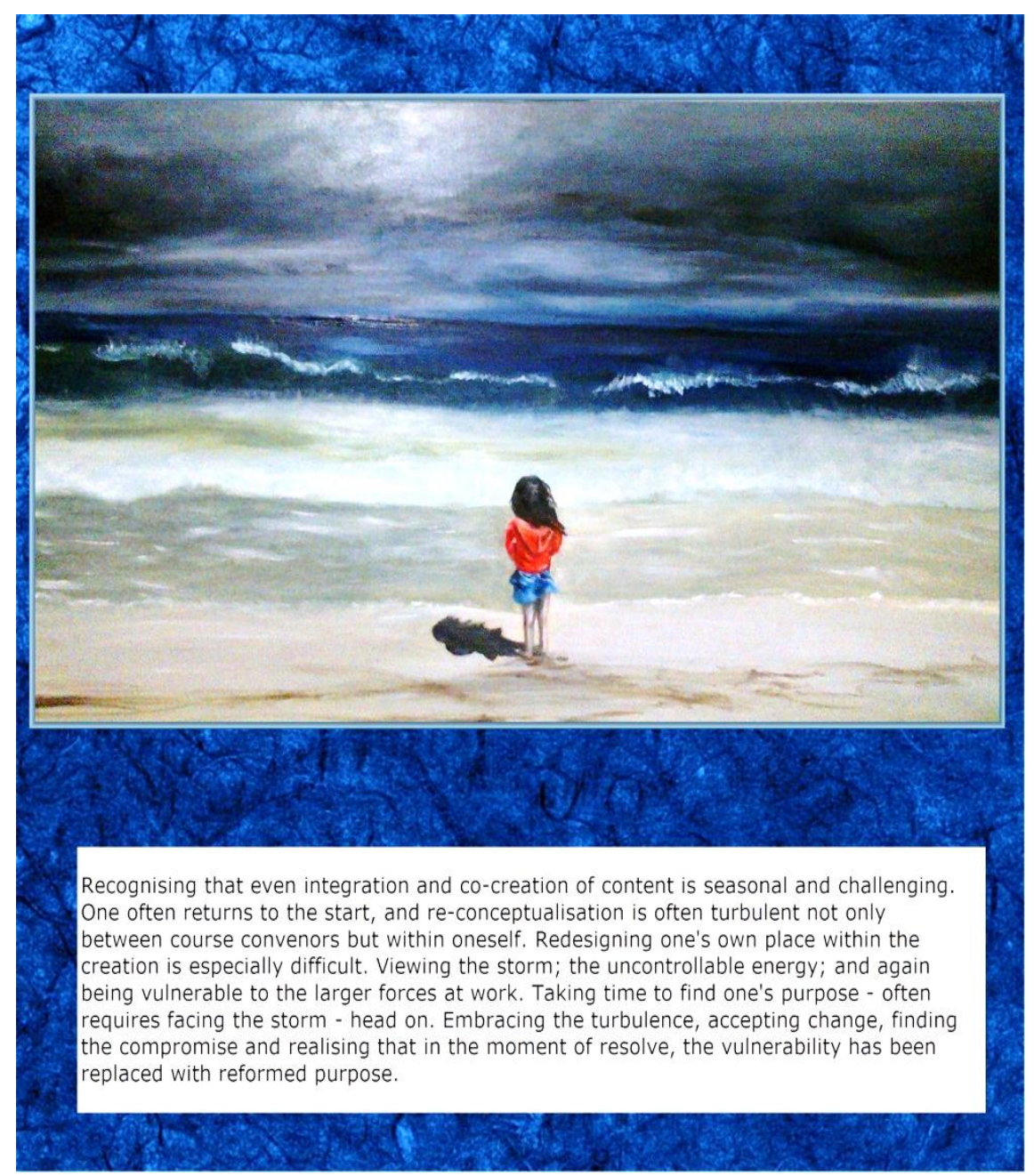

Figure 4: Sianne's scrapbook page, 'Transform'

I then decided to paint three images that depicted my journey as an HIV educator. During this process I was drawn to colours that mirrored my emotions, such as dark vivid imagery that reflected my anxiety about addressing HIV apathy. These colours lightened as the anxiety faded away, and the content and pedagogy that was conceptualised began to produce effective results 
in knowledge generation among the students. After the paintings were complete I took photographic images of them and uploaded them into the Smile scrapbook software. The paintings became the focal point of the scrapbook page and depicted images of the journey from conceptualisation through to completion.

Explanatory text within the scrapbook described the purpose of the image. These texts were placed underneath or to the side of the image - so to not detract from the image itself.

I then began to choose embellishments that complemented the images. Embellishments included layering ribbon, paper, and symbols. I was also able to use the colour exposure tool to emphasise patterns embedded in the scrapbook paper. The scrapbooking journey produced rewards and challenges that paralleled the discourse that educators are currently facing, as universities move towards online spaces for education.

\section{Reflecting on the scrapbook pages}

After we had completed our own scrapbook pages we circulated the pages via e-mail to each team member, and individually examined each other’s scrapbook pages. On 21 November 2014 Linda e-mailed the following suggested reflection format to the team:

Please look at the attached scrapbook pages.

Individually decide on and reflect on how the designer of ... [title of scrapbook page] represented/portrayed:

1. herself in the scrapbook page

2. students in the scrapbook page

3. the process of HIV and AIDS curriculum integration.

Each team member then prepared a written reflection on the scrapbook pages created by the other three team members. We reflected on who or what represented: the HIV and AIDS curriculum integrator; her students; and the integration process.

Only after we had circulated our reflections on each other's scrapbook pages did the creator of each scrapbook page disclose her intended representations on her own scrapbook page.

\section{WHAT OUR SCRAPBOOKS REVEALED}

Linda described her scrapbook page, 'My HIV and AIDS integration journey’ (Figure 1), as follows:

I used a photograph of me walking on a road to illustrate my professional journey. The dotted line on the road symbolises my initiatives in HIV and AIDS curriculum integration in Mathematics Education. The students are represented by the hand-drawn pictures of pre-service teachers. The process of integration occurred as I introduced the pre-service teachers to a set of integrated learner 
mathematics activities, which I had devised, that were appropriate for teaching young learners in the South African context. The integrated process is illustrated by the pictures showing the world map of HIV statistics and the 'No one dies of AIDS' (Venter and Brown 2005) caption of a newspaper article.

Kathleen reflected on her scrapbook page, 'Me and HIV and AIDS' (Figure 2):

The integration process involves composing and sharing narratives of personal and professional experiences and concerns in relation to HIV and AIDS. The page highlights how I as an educator have become increasingly aware of the emotionality and emotional responsibility of bringing awareness of personal and professional selves to the topic of HIV and AIDS, which is experienced so painfully by so many South Africans. The page also reveals some of my students' (all practising teachers) thoughts about the value and nature of the personal and professional learning that can occur through bringing self-awareness to HIV and AIDS in education.

Cal explained her page, 'Youth art/health Xchange' (Figure 3), in this way:

I am symbolically reflected as the heart growing out of the tree. I work in HIV and AIDS because I do not want the challenge of HIV and AIDS to affect South Africans' hopes and dreams for a better life.

The image of the young boy carrying the flag reflects the youth in South Africa. Issues related to HIV and AIDS affect young people dramatically. This large flag represents the heavy burden of HIV and AIDS on South African youth. The flag with all the strands represents the different aspects of HIV and AIDS that I strive to include in HIV and AIDS education. These aspects relate to factors affecting one's personal relationships; how HIV and AIDS can influence one's behaviour towards one's family, social circle, workplace and community. The process of curriculum integration is through using and teaching with images and technology that is reflected in youth culture. The words 'youth project' and the girl using her fingers as if on a keyboard represent the integration processes used to capture the students' attention.

Sianne offered this elucidation of her scrapbook page, 'Transform' (Figure 4):

I am represented by the girl observing the imminent storm as I reconceptualise what HIV content should be included in a course that speaks to the intersections between HIV and race, class, gender, sexuality, disability and other social issues. Developing relevant content that captures the nuances of HIV and its related intersections is a major part of being a HIV curriculum development officer. The storm is analogous to the task of reframing the curriculum. The waves and clouds represent the multi-layered complexities experienced by our students who bring to the classroom their opinions and beliefs that influence how they interpret the HIV content shared in the curriculum. The structured separation between sand, sea and sky that merges visually from one boundary to the next symbolises my phased approach in grappling with, reworking, conceptualising and returning to curriculum initiatives that are taught in the various courses in Engineering, Science, Commerce and Humanities.

\section{BRINGING OUR PROFESSIONAL LEARNING TOGETHER}

To start a process of bringing our learning into dialogue, Cal prepared a summary of our written reflections on our own and each other's scrapbook pages, highlighting convergence and divergence. Kathleen then went back to the reflections that each of us wrote on each other's 
and our own scrapbook pages, to look specifically at what we had written in relation to our experiences of 'being a professional in practice' (Webster-Wright 2009, 725) in diverse contexts of HIV and AIDS curriculum integration in higher education. Kathleen copied and pasted those 'scraps' from our varied reflections into a collective composite text (Figure 5) (Pithouse-Morgan 2016).

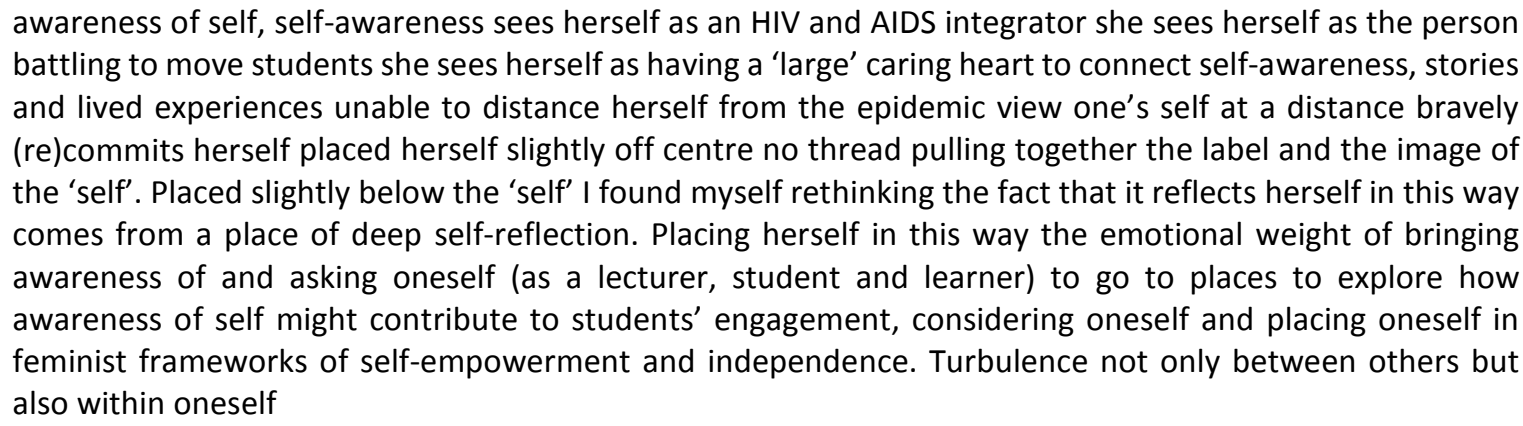

Figure 5: An extract from the composite text of our professional learning reflections

Kathleen drew from the composite text to create a found poem (Figure 6), which is a poem created through finding words and phrases in other texts and rearranging these words and phrases into poetic form (Butler-Kisber 2005). This poem, Portrait of an HIV and AIDS integrator, portrays commonalities across our diverse reflections on HIV and AIDS curriculum integration within different disciplinary and institutional contexts. The curriculum integrator depicted in the poem is thus a multifaceted portrayal of the four of us. Butler-Kisber (2005, 108) explains that such an auto/biographical poetic representation of researchers' own reflections can allow 'deeper understanding of research interest and stance' to surface, 'which might remain dormant while using other more linear reflective tools such as memos or journals'.

\section{Found poem \\ Portrait of an HIV and AIDS integrator}

Unable to distance her self

The emotional weight

Turbulent within her self

Placed her self

Off centre

Self-empowerment

Comes from

Deep self-reflection

Re-thinking her self

Asking her self

To go to places

To connect, engage

Figure 6: A found poem: Portrait of an HIV and AIDS integrator 
Kathleen emailed the found poem to the other team members and asked them to send written reflections on the poem.

\section{FRAMING OUR INDIVIDUAL AND COLLECTIVE LEARNING}

In making meaning from our scrapbook pages and the found poem Portrait of an HIV and AIDS integrator, we returned to three themes that we had identified in previous research on professional learning experiences of other academics who take up HIV and AIDS curriculum integration in diverse academic disciplines: 'selfing, distancing and valuing' (Van Laren et al. 2012, 138). By considering the summary of our reflections on each other's scrapbook pages and our own responses to our own scrapbook pages that was prepared by Cal, together with our reflections on the found poem, we now framed our responses in relation to the three themes. The quotations in the following sections are taken from our written reflections on the poem Portrait of an HIV and AIDS integrator.

\section{Selfing}

Here we explore how we depicted ourselves in the scrapbooking pages and in the poem as being transformed to facilitate HIV and AIDS curriculum integration. Sianne reflected that the HIV and AIDS integrator portrayed in the poem found 'devolving' her identity to be a critical component of engaging the lecture space as she 'placed her self / off centre' (lines 4-5). She thus had to recognise and make 'invisible' her privileges of class, race and gender that she brought into the lecture situation. By 're-thinking her self / asking her self / to go to places' (lines 9-11), the HIV and AIDS integrator was able to engage with the content freely and feel 'unjudged'.

Furthermore, Linda reflected that making differences in a 'close to the heart' curriculum integration initiative caused the HIV and AIDS integrator to feel uneasy about her competencies - particularly because the complex issue of HIV and AIDS curriculum integration is difficult to resolve fully. Whilst she felt confident and at ease teaching the discipline in which she was familiar and qualified, she had to develop additional, unfamiliar academic content knowledge to include the sensitive issue of HIV and AIDS education. The curriculum integrator therefore had to confront the 'self' of her personal and professional lives, and this resulted in risk and challenges: 'turbulent within her self' (line 3).

Sianne commented that the HIV and AIDS integrator thus had to forsake her former professional identity when taking on HIV and AIDS curriculum integration: 'placed her self / off centre' (lines 4-5). She had to move her 'current perspective to a wider' sensitive context 
through actively 'seeking alternative ways' of presenting academic content knowledge: 'asking her self / to go places / to connect, engage' (lines 10-12).

Linda reflected on how her scrapbook page revealed that her integration journey necessitated taking risks, as the HIV and AIDS curriculum integration may seem to be 'straightforward but there are often unexpected curves and turn in the road'. Likewise, she proposed that the image of the heart on Cal's scrapbook page showed connections to the lives of people. She indicated that her own journey of integration was sometimes 'tranquil' and at other times felt 'dangerous'.

In addition, in commenting her scrapbook page Kathleen explained that she had not fully anticipated the emotional weight of inviting students to reflect on their selves and their experiences of HIV and AIDS. She had had to face her own emotions while listening and responding to students' 'experiences of suffering and loss'.

\section{Distancing}

In this theme we explore how we represented ourselves on the scrapbook pages and in the poem as having stretched boundaries for HIV and AIDS curriculum integration: 'to go to places / to connect, engage' (lines 11-12) beyond conventional academic disciplinary boundaries. Cal indicated that the image of two sides of a face in her scrapbook page meant that the curriculum designer needs to restructure the prescribed curriculum to extend discipline outcomes to include more intangible capacities such as empathy. She explained that the image of a two-sided face also illustrated how the boundaries for HIV and AIDS curriculum integration require stretching, so that the roles she played were multifaceted: she needed to make students aware of the dangers of HIV and AIDS and simultaneously instil hope and optimism. In addition, her image of the large heart illustrated how discipline 'veins and arteries' needed to be connected to the caring 'heart' during HIV and AIDS curriculum integration.

Kathleen described how her scrapbook page highlighted overlaps between the lived experiences of the HIV and AIDS curriculum developer and the students. This meant that boundaries between being an academic and a student became blurred in relation to the HIV and AIDS pandemic. In her scrapbook page reflection, Sianne reiterated that 'linkages between race, gender, sexuality and economy provide discursive platforms that begin to shape the lecture spaces'. Such linkages necessitate stretching or blurring of boundaries of being academics and students in the HIV and AIDS integrated curriculum: ‘to connect, engage’ (lines 11-12). 


\section{Valuing}

For this theme we consider how we illustrated on the scrapbook pages or indicated in the poem how we valued and persisted in 'self-empowerment' (line 6) to improve our practices for HIV and AIDS curriculum integration. Linda reflected that she constantly self-reflected in searching for alternative ways of improving her practice in relation to the pandemic. She described the photograph on her scrapbook page as showing her on an extended journey where she is actively moving forward. Linda also commented on how the found poem emphasised how emotional, challenging and sometimes uncomfortable responsibilities had not deterred the curriculum integrator in her endeavours to make a difference.

Sianne explained how her scrapbook page showed ever-changing images of the sea to illustrate and make sense of the moving changes she observed in HIV and AIDS curriculum integration. Cal's scrapbook image of a moving boy pulling and unravelling fabric was interpreted by Kathleen as an 'intricately designed piece of woven cloth' that 'has been made with care and attention to detail'. Kathleen elucidated that this suggested that HIV and AIDS curriculum integration requires 'meticulous artistry as well as exertion and movement'. Linda considered the 'enormous job' of the curriculum integrator as being portrayed in this image where the boy is 'struggling to drag the students (represented by the flag) along with her.' The taxing work of the curriculum integrator sometimes requires students and academics to see the need to change from familiar ways and move in another direction.

We also reflected on the relentlessness of the HIV and AIDS pandemic, symbolised in the use of powerful colours in the images chosen by two of the authors for their scrapbook pages. However, we felt that the colourful golden buttons on Linda's scrapbook page and Kathleen's use of clusters of coloured flowers showed that through persistent work in the context of the pandemic, transformation was not always merely ‘gloom and doom’ (Linda). As Sianne reflected on her scrapbook page:

We have to work with an epidemic that is largely influenced by so many variable factors. These factors are at times dangerous and powerful, but are also capable of being managed if certain safety and prevention mechanisms are adhered to.

\section{SCRAPBOOKING AS A TOOL FOR PROFESSIONAL LEARNING}

Here we return to our guiding research question: How can making and reflecting collaboratively on scrapbook pages serve as a tool for professional learning about HIV and AIDS curriculum integration in higher education?

Using the scrapbook pages to reflect on our own and each other's portrayals of our lived experiences furthered our individual and collaborative professional learning. Using visual 
images for exploring data collaboratively benefitted the research process (Harper 2002). However, before we were able to commence with exploring our collaborative experiences in HIV and AIDS curriculum integration, we each needed to create our own scrapbook page. We each spent a considerable amount of time selecting appropriate visual images for our scrapbook pages. Because a limited number of images could be used for a page, each researcher had the task of making sure that her individual selections were significant in relation to her own experiences of HIV and AIDS curriculum integration. Selecting these visual images necessitated surveying her years of involvement in curriculum integration and limiting her choices. This means that only images that were memorable and important to her professional learning were chosen to be highlighted on her particular scrapbook page.

Furthermore, when we each came to create our scrapbook page it told a story about our professional learning in HIV and AIDS curriculum integration. Our particular scrapbook page served as a 'one pager' representing noteworthy aspects of our professional learning as teachers/lecturers of students in relation to the teaching and learning context of the pandemic. The resulting scrapbook page of each of us thus focused on personally significant events (Reynolds 2010) in our professional learning.

In addition, the medium chosen by each professional was uniquely different and connected to the researchers' personal preferences and professional experiences. Each researcher could create and craft her scrapbook page through her preferred medium. For example, Linda preferred to use textured background paper together with concrete objects and glossy photographs, whereas Cal made use of a collage of digitally recorded graffiti. This flexibility in selecting an appropriate scrapbook medium that suited each researcher's particular capabilities allowed for creative expression of her own professional experiences. Thereafter we each interpreted the images in a manner that we considered fitting to connect our teaching and learning of HIV and AIDS curriculum integration in our higher education context. Our research therefore illustrated how creativity in educational research can be enhanced when we are not 'compelled to work within overly constraining expectations — of ourselves and of others' (Katz 2015, 19).

Reflecting on each other's scrapbook pages facilitated further insight into our own professional experiences and those of the other team members. Thus the scrapbook pages provided us with a creative way of connecting, sharing and reflecting (Hunting and Conroy 2011). The bringing together of our professional learning experiences allowed us to condense common reflection strands into our found poem Portrait of an HIV and AIDS integrator. The poetic representation of our reflections in turn sanctioned disclosure of common understandings 
(Butler-Kisber 2005) that are often not openly discussed in relation to our professional learning in HIV and AIDS curriculum integration.

Katz (2015) writes that creativity is increased when one is not confined to meeting expectations that begin to constrain progress. We found the scrapbooking process to be a useful mechanism of 'sorting through' our own challenges in being an HIV educator - and this reflexivity helped us consider how we might devolve power to the students within the lecture space, whilst we facilitated their learning. However, the success of this approach was dependent on the educator researching new content and information that affects students in both their personal and professional capacities. The scrapbook method helped us to think of more interactive and creative ways in which we might address such challenges. As indicated through the expressions of the authors, there were shifts in our thinking about 'ourselves' as educators, and the pedagogy and use of technology that we use to educate students about HIV. The scrapbook method brought to the surface the implicit desire to legitimize HIV education, by reframing the HIV content; increasing interaction in class and inviting students to critically reflect about HIV in a broader contextual way.

We found that when planning to teach integrated lessons that would interest students in a professional aspect, we often neglected to set aside time to reflect on our own positioning in relation to HIV and AIDS. Through collective reflection, using our scrapbook pages, we felt less pressured and comforted by being able to share the responsibility of integration. We did not become less committed to curriculum integration, but we became more interested in how the emotional burden of HIV and AIDS could be shared.

\section{CLOSING}

Through working collaboratively using scrapbook pages we came to realise that as academics our professional learning as HIV and AIDS curriculum integrators constantly undergoes transformation as we connect our personal and academic knowledge. In addition, as curriculum integrators we continually pursue appropriate ways of being professionals whilst responding to the needs and interests of students in the HIV and AIDS context.

Our scrapbooking process has highlighted that the complex, pervasive nature of the pandemic need not result in the attitude that there is nothing that can be done. By using the creative method of scrapbooking we were collectively able to make use of the therapeutic benefits of scrapbooking activities to explore and extend our own professional learning in the company of supportive others. 


\section{REFERENCES}

Belk, R. W. and R. V. Kozinets. 2005. Videography in marketing and consumer research. Qualitative Market Research 8(2): 128-141.

Butler-Kisber, L. 2005. Inquiry through poetry: The genesis of self-study. In Just who do we think we are? Methodologies for autobiography and self-study in teaching, ed. C. Mitchell, S. Weber and K. O’Reilly-Scanlon, 95-110. London: RoutledgeFalmer.

De Lange, N. 2014. HIV and AIDS education Community of Practice (CoP). http://rce.nmmu.ac.za/HIVand-AIDS-Education-Community-of-Practice (accessed 10 October 2013).

Dewey, J. 1938/1997. Experience and education. New York: Touchstone.

Enright, E. and M. O’Sullivan. 2011. 'Producing different knowledge and producing knowledge differently': Rethinking physical education research and practice through participatory visual methods. Sport, Education and Society 17(1): 35-55.

Harper, D. 2002. Talking about pictures: A case for photo elicitation. Visual Studies 17(1): 13-26.

HEAIDS see Higher Education HIV and AIDS Programme.

Higher Education HIV and AIDS Programme. 2010. Curriculum-in-the-making-Being a teacher in the context of the HIV and AIDS pandemic - Teacher Education Pilot Project. Pretoria: Higher Education South Africa.

Higher Education HIV and AIDS Programme. 2012. Policy and strategic framework on HIV and AIDS for Higher Education. Pretoria: Higher Education HIV/AIDS Programme.

Hinde, E. T. 2005. Revisiting curriculum integration: A fresh look at an old idea. Social Studies 96(3): 105-111.

Hunting, M. and D. Conroy. 2011. The visual component: Use of images to enhance multimodal research. ANZMAC. http://ejournal.narotama.ac.id/files/The\%20Visual\%20Component\%20 Use\%20of\%20Images\%20to\%20Enhance\%20Multimodal\%20Research.pdf (accessed 2 July 2015).

Jones, M. M. 2007. An ethnographic exploration of narrative methodologies to promote the voice of students with disabilities. Journal of Ethnographic \& Qualitative Research 2(1): 32-40.

Katz, L. 2015. Doubt, ambivalence, and creativity in academia. Journal of Artistic and Creative Education 9(1): 8-21.

Kohut, M. 2011. Making art from memories: Honoring deceased loved ones through a scrapbooking bereavement group. Art Therapy 28(3): 123-131.

McCarthy, P. G. and J. G. Sebaugh. 2011. Therapeutic scrapbooking: A technique to promote positive coping and emotional strength in parents of pediatric oncology patients. Journal of Psychosocial Oncology 29(2): 215-230.

Michaels, A. 2010. The winter vault. New York: Vintage Books.

Mitchell, C. 2011. Doing visual research. London: Sage.

Parker, W. C. 2005. Social studies in elementary education. 12th ed. Columbus, OH: Pearson Merrill, Prentice-Hall.

Pithouse, K. 2007. Learning through teaching: A narrative self-study of a novice teacher educator (PhD thesis). University of KwaZulu-Natal, Durban.

Pithouse-Morgan, K. 2016. Finding my self in a new place: Exploring professional learning through found poetry. Teacher Learning and Professional Development 1(1): 1-18. http://journals.sfu.ca/ tlpd/index.php/tlpd/article/view/1 (accessed 1 July 2016).

Pithouse-Morgan, K. and A. P. Samaras. 2015. The power of 'we' for professional learning. In Polyvocal professional learning through self-study research, ed. K. Pithouse-Morgan and A. P. Samaras, 120. Rotterdam: Sense Publishers.

Reynolds, D. M. 2010. Beyond scraps: Narrating traumatic health experiences through scrapbooking 
(PhD thesis). University of Maryland, College Park, Maryland. http://hdl.handle.net/1903/10281 (accessed 8 April 2016).

Savage, A. 2014. Why I love graffiti. https://angelasavage.wordpress.com/2014/01/13/why-i-lovegraffiti/ (accessed 8 April 2016).

Simbayi, L. C., O. Shisana, T. Rehle, D. Onoya, S. Jooste, N. Zungu, D. Labadarios and K. Zuma. 2014. South African national HIV prevalence, incidence and behaviour survey, 2012. Pretoria: Human Sciences Research Council.

Van Laren, L. 2008. Starting with ourselves: Addressing HIV and AIDS education through integration in a South African pre-service teacher mathematics education curriculum. ( $\mathrm{PhD}$ thesis). University of KwaZulu-Natal, Durban.

Van Laren, L., C. Mitchell, R. Mudaly, K. Pithouse-Morgan and S. Singh. 2012. Exploring university educators' lived experiences of curriculum innovating through integrating HIV \& AIDS. Alternation 19(2): 138-161.

Van Laren, L., K. Pithouse-Morgan, T. Chisanga, L. Harrison, T. Meyiwa, N. Muthukrishna et al. 2014. 'Walking our talk': Exploring supervision of postgraduate self-study research through metaphor drawing. South African Journal of Higher Education 28(2): 639-659.

Venter, B. and K. Brown. 2005. No one dies of AIDS. The Independent on Saturday, February 19:1.

Webster-Wright, A. 2009. Reframing professional development through understanding authentic professional learning. Review of Educational Research 79(2): 702-739.

Williams, K. and J. Lent. 2008. Scrapbooking as an intervention for grief recovery with children. Journal of Creativity in Mental Health 3(4): 455-467. 